\title{
UNCERTAINTY AND OPTIMALITY
}

Probability, Statistics and Operations Research 
This page is intentionally left blank 

Published by

World Scientific Publishing Co. Pte. Ltd.

P O Box 128, Farrer Road, Singapore 912805

USA office: Suite 1B, 1060 Main Street, River Edge, NJ 07661

UK office: 57 Shelton Street, Covent Garden, London WC2H 9HE

\section{British Library Cataloguing-in-Publication Data}

A catalogue record for this book is available from the British Library.

\section{UNCERTAINTY AND OPTIMALITY \\ Probability, Statistics and Operations Research}

Copyright $(\mathcal{C} 2002$ by World Scientific Publishing Co. Pte. Ltd.

All rights reserved. This book, or parts thereof, may not be reproduced in any form or by any means, electronic or mechanical, including photocopying, recording or any information storage and retrieval system now known or to be invented, without written permission from the Publisher.

For photocopying of material in this volume, please pay a copying fee through the Copyright Clearance Center, Inc., 222 Rosewood Drive, Danvers, MA 01923, USA. In this case permission to photocopy is not required from the publisher.

ISBN 981-238-082-5

Printed in Singapore by Uto-Print 


\section{Preface}

This really is the golden age of Mathematics. It has been said that half the Mathematics ever created has been in the last 100 years and that half the mathematicians who have ever lived are alive today. We have seen such achievements as the resolution of the four-colour problem and Fermat's last theorem, with the latter being a special manifestation of a much more general result!

It is befitting that the golden Jubilee of the Indian Institute of Technology Kharagpur, happens to fall in the golden age of Mathematics. As a senior professor in the Department of Mathematics, I felt encouraged to bring out a series of books covering all the major areas of Mathematical Sciences during this period of historic importance.

This book is an important member of the aforesaid series and consists of chapters that deal with important topics in Biomathematics. A glance through any modern textbook or journal in the fields of ecology, genetics, physiology or biochemistry reveals that there has been an increasing use of mathematics which ranges from the solution of complicated differential equation in population studies to the use of transfer functions in the analysis of eye-tracking mechanisms. This volume deals with Applied Mathematics in Biology and Medicine and is concerned with applied mathematical models and computer simulation in the areas of Molecular and Cellular Biology, Biological Soft Tissues and Structures as well as Bio-engineering.

In this volume an attempt has been made to cover biological background and mathematical techniques whenever required. The aim has been to formulate various mathematical models on a fairly general platform, making the biological assumptions quite explicit and to perform the analysis in relatively rigorous terms. I hope, the choice and treatment of the problems will enable the readers to understand and evaluate detailed analyses of specific models and applications in the literature.

The purpose of bringing out this volume on Biomathematics dealing with interdisciplinary topics has been twofold. The objectives are to promote research in applied mathematical problems of the life sciences and to enhance cooperation and exchanges between mathematical scientists, biologists and medical researchers. This volume has both a synthetic and analytic effect. The different chapters of the volume have been mostly concerned with model building and verification in different areas of biology and the medical sciences.

I believe, people in the entire spectrum of those with an interest in ecology, from field biologists seeking a conceptual framework for their observations to mathematicians seeking fruitful areas of application, will find stimulation here. It may so happen that some readers may find some parts of this volume trivial and some of the parts incomprehensible. Keeping this in view extensive bibliographies have been given at the end of each chapter which do attempt to provide an entry to the corresponding areas of study.

For over three decades I have been engaged in teaching and research at several well-known institutions of India, Germany and North America. Publication of the series of books has been the fruit of a long period of collaboration together with relentless perseverance. It has been our endeavour to make these books useful to a large section of people interested in mathematical sciences, professional as well as amateur. The volumes have been so designed and planned that illustrative examples and exercises as well as fairly comprehensive bibliography are included 
in the various chapters. This will help strengthen the level of understanding of the learners. Thus the books of this series will be of interest not only to graduate students but also to instructors, research scientists and professionals. The volumes of the series might not exactly serve as textbooks, but will definitely be worthwhile supplements. Our labour will be deemed amply rewarded if at least some of those for whom the volumes are meant derive benefit from them.

I am thankful to the members of the ICRAMS committee for their kind encouragement in publishing the mathematical science series on the occasion of the Golden Jubilee of our Institute. I feel highly indebted to the contributors of all the volumes of the series who have so kindly accepted my invitation to contribute chapters. The enormous pleasure and enthusiasm with which they have accepted my invitation have touched me deeply, boosting my interest in the publication of the series.

I. I. T. Kharagpur

J. C. Misra 


\section{About the Editor}

Dr. Jagadis Chandra Misra, Senior Professor at the Department of Mathematics, Indian Institute of Technology Kharagpur, received his Ph.D. degree in Applied Mathematics from Jadavpur University in 1971. Subsequently the University of Calcutta conferred on him the coveted D.Sc. degree in Applied Matbematics in year 1984. For over three decades he has been engaged in teaching and research at several distinguished institutions of India, Germany and North America. He has been the Chairman of the Department of

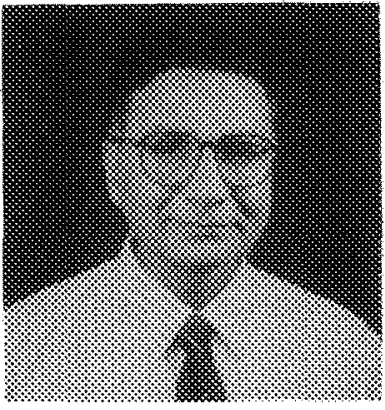
Mathematics, IIT Kharagpur during the period 1998-2001. As a recipient of the Humboldt Fellowship he was at the University of Hannover during the period 197577 and also in 1982, where he carried out his research in the field of Biomechanics in collaboration with Professor Oskar Mahrenholtz of the University of Hannover and the Professor Christoph Hartung from the Biomedical Engineering Division of the School of Medicine, Hannover. He has held the position of Visiting Professor at the University of Calgary, Canada and also at the Indian Institute of Technology, Kanpur. He also paid brief visits to Cambridge University, Oxford University, Manchester University, Glasgow University, University of Paris, Ecole Polytechnique in France, Graz University in Austria, Delft University in the Netherlands, University of California, Los Angeles and University of California, San Diego. In 1984 he received the prestigious Silver Jubilee Research Award from IT Kharagpur, his research publications having been adjudged to be outstanding. He has been elected a Fellow of the National Academy of Sciences in 1987, the Institute of Mathematics and its Applications (UK) in 1988, the Institute of Theoretical Physics in 1988, the Royal Society of Medicine, London in 1989 and the Indian National Academy of Engineering in 1999. Professor Misra has to his credit over 140 research publications in journals of international repute; he has also published several advanced level books. Most of his research investigations in the field of Biomathematics have appeared in highly prestigious journals like Journal of Mathematical Biology (USA), Bulletin of Mathematical Biology (UK), Journal of Biomechanics (UK), Journal of Biomedical Engineering (UK), Blood Vessels (Switzerland), Rheologica Acta (Germany), Biorheology (UK), International Journal of Solids and Structures (UK), International Journal of Nonlinear Mechanics (UK) etc. His publications have been well cited in the scientific literature. He has made pioneering research on mathematical modelling in each of the areas of Cardiovascular Mechanics, Mechanics of Brain Injury, Mechanics of Fracture and Remodelling of Bones and Peristaltic Flows in Physiological Systerns. His theoretical findings on the compressibility of vascular tissues is a major breakthrough in the study of arterial biomechanics and were subsequently verified experimentally by Prof. Y. C. Fung of the University of California, San Diego. The Model developed by him for the study of arterial stenosis bears the potential to provide an estimate of the variation of blood viscosity as the height of the stenosis increases. The observations of the study were used by later investigators in the quantification of Doppler colour flow images from a stenosed carotid artery. Misra's theoretical study on the mechanics of cerebral concussion caused due to rotational acceleration of the head has opened up new 
vistas in neurological research and neurosurgery. On the basis of the study he could make some valuable predictions regarding the threshold of cerebral concussion for humans, in terms of angular accelerations. He was the first to account for the effect of material damping of osseous tissues on bone remodelling induced due to the surgical procedure of intra-medullary nailing. Misra's recent study on the effect of a magnetic field on the flow of a second-grade electrically conducting fluid serves as a very important step towards the perception of MHD flow of blood in atherosclerotic vessels. It throws sufficient light on the quantitative features of blood flow in constricted arteries.

Professor Misra has guided 20 research scholars towards their Ph.D. degree. He has been a member of the expert committee of the Council of Scientific and Industrial Research, New Delhi, of the Indira Gandhi National Open University and also of the National Science Foundation of USA as well as a member of the Technical Advisory Committee of the Indian Statistical Institute, Calcutta. In the year 1981 he delivered invited lectures at the Courant Institute of Mathematical Sciences, New York, at Cornell Medical Center, New York, at Kobe University, Japan and also at the Fourth International Congress of Biorheology held in Tokyo. Professor Misra delivered the prestigious Bhatnagar Memorial Lecture in 2001. He has been invited to deliver a lecture and to chair a session at the Fifth International Congress of Biorheology held in Germany in 1983, at the Tenth International Conference of Industrial and Applied Mathematics held in Belgium in July 2002 and also to deliver a keynote address and to chair a session at the International Conference on Applied Mathematics \& Mathematical Physics held in Bangladesh in November 2002. 


\section{Contents}

Preface $\quad$ v

The Editor vii

Chapter 1 Towards A Non-subjective Bayesian Paradigm 1 J. K. Ghosh and T. Samanta

Chapter 2 On Some Problems of Estimation for Some Stochastic Partial Differential Equations

B. L. S. Prakasa Rao

Chapter 3 Some Unifying Techniques in the Theory of Order Statistics H. A. David

Chapter 4 Stochastic Orderings among Order Statistics and Sample Spacings

B.-E. Khaledi and S. Kochar

Chapter 5 Parametrics to Nonparametrics: Extending Regression Models

A. Sarkar

Chapter 6 Testing Goodness of Fit of a Specific Parametric Probability Model

J. V. Deshpande and U. V. Naik-Nimbalkar

Chapter $7 \quad U$ Statistics and $M_{m}$ Estimates

A. Bose

Chapter 8 Parametric Inference with Generalized Ranked Set Data

B. C. Arnold and R. J. Beaver

Chapter 9 Fisher Information in the Farlie-Gumbel-Morgenstern Type Bivariate Exponential Distribution

H. N. Nagaraja and Z. A. Abo-Eleneen

Chapter 10 Classification Invariance in Data Envelopment Analysis

L. M. Seiford and J. Zhu 
Chapter 11 A Useful Isometry for Time Reversible Markov Chains, with Applications to Reliability

M. Brown

Chapter 12 Information Theoretic Approach to Statistics

J. N. Kapur

Chapter 13 Mean Square Error Estimation in Survey Sampling

A. Chaudhuri

Chapter 14 Linear Programming: Recent Advances

S. K. Sen

Chapter 15 Operations Research in the Design of Cell Formation in Cellular Manufacturing Systems

E. S. Lee and P.-F. Pai

Chapter 16 Scheduling Problems in Large Road Transport

Corporations: Some Experiences in Structuring and

Modeling

S. Ankolekar, V. L. Mote, N. R. Patel and J. Saha

Chapter 17 Optimal Shutdown Policies for a Computer System based on the Power-Effective Design

H. Okamura, T. Dohi and S. Osaki

Chapter 18 Local Search Heuristics for Combinatorial Optimization Problems

A. K. Mittal 